\title{
PoLÍtICAS PÚBLICAS \\ E DIREITOS FUNDAMENTAIS \\ DOS TRABALHADORES \\ RURAIS NA AGRICULTURA \\ CANAVIEIRA PAULISTA

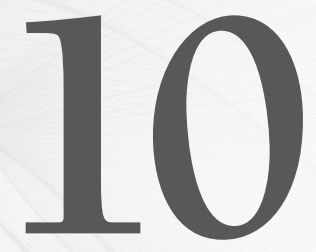

inserida em um contexto de desenvolvimento sustentável

Public policy and fundamental rights of rural workers in agriculture sugarcane of São Paulo inserted in a context of sustainable development

\section{Awdrey Frederico Kokol}

Mestre em Direito pela Universidade Metodista de Piracicaba - Unimep. Advogada.

\section{MirTa LeRena MisaiLIDIS}

Doutora pela PUC-SP. Professora e Coordenadora do Programa de Mestrado em Direito da Universidade Metodista de Piracicaba - Unimep.

\section{José Fernando Vidal de Souza}

Pós-doutor pela Universidade de Coimbra. Doutor em Relações Sociais (Direito Ambiental) e Mestre em Relações Sociais (Direito Penal) pela PUC-SP. Especialista em Ciências Ambientais pela Universidade São Francisco. Bacharel em Filosofia pela PUC-Camp. Professor de Graduação e Pós-graduação da Universidade Metodista de Piracicaba Unimep e de Graduação da Universidade Paulista - Unip. Promotor de Justiça no Estado de São Paulo. 
ÁreA do DiReito: Ambiental; Trabalho

Resumo: A pretensão deste trabalho é examinar os direitos fundamentais dos trabalhadores no setor sucroalcooleiro no momento atual, frente ao crescimento da atividade no mercado internacional e a busca por fontes alternativas de energia ajustadas às políticas de sustentabilidade. 0 crescimento do setor deve-se à produção de energia a partir do bagaço da cana-de-açúcar, como forma de substituição aos combustiveis fósseis. Para tanto a atividade canavieira busca ganhar o mercado mundial, tornando-se uma commodity. Com isso, o empenho do Estado e dos usineiros é no sentido de implementar medidas de mecanização da colheita da cana-de-açúcar em substituição à utilização da força de trabalho manual. Esta opção, no entanto, gerará desemprego em massa de trabalhadores, com aumento significativo de problemas sociais nas cidades produtoras. Atrela-se ao fato a análise do desenvolvimento sustentável no setor sucroalcooleiro, em decorrência das práticas antissociais e nocivas ao meio ambiente, próprias e comuns na atividade canavieira. Assim, o objetivo não é outro senão cotejar aspectos da indústria canavieira e a sua introdução na agenda do desenvolvimento econômico sustentável, sob a ótica dos direitos fundamentais do trabalhador e as políticas públicas e sociais propostas pelos atores envolvidos.

Palavras-chave: Trabalhadores rurais - Cana-de-açúcar - Desenvolvimento sustentável - Políticas públicas e sociais.
ABSTRACT: The intention of this paper is to examine the fundamental rights of workers in the alcohol sector at present, compared to the activity growth in the international market and the search for alternative sources of energy adjusted to sustainability policies. The sector's growth is due to energy production from bagasse from sugar cane as a means of replacing fossil fuels. For both sugar production seeks to win the world market, becoming a commodity. Thus, the commitment of the State and mill owners is to implement measures of mechanization of cane sugar instead of using manual labor. This option, however, will generate massive unemployment of workers, with significant increase of social problems in producing cities. Binds to the fact that the analysis of sustainable development in the biofuels industry, due to anti-social behavior and practices harmful to the environment, own and common in sugar. The aim is none other than to compare aspects of the sugar industry and its inclusion in the agenda of sustainable economic development from the perspective of fundamental rights of workers and the public and social policies proposed by the actors involved.

KEYWORDS: Rural workers - Sugarcane - Sustainable development - Public and social policies.

SumÁRIO: 1. Introdução - 2. Os direitos dos trabalhadores no constitucionalismo social do século XX - 3. A agricultura canavieira e as controvérsias sobre sua sustentabilidade nas relações de trabalho - 4. Políticas públicas para a mecanização da colheita da cana-deaçúcar - 5. Considerações finais - 6. Referências.

\section{INTRODUÇÃO}

A proposta do presente trabalho é apresentar as questões relativas aos direitos fundamentais dos trabalhadores no setor sucroalcooleiro no momento em que a atividade vem ganhando espaço no mercado internacional devido às demandas por fontes alternativas de energia que se ajustem às políticas de sustentabilidade. 
A expectativa sobre o setor faz-se devido à da produção de energia a partir do bagaço da cana-de-açúcar em substituição a utilização de combustíveis fósseis. Para que a atividade canavieira ganhe o mercado mundial é preciso que o etanol se torne uma commodity, e para tanto, governantes e usineiros têm empenhado medidas viabilizadoras da mecanização da colheita da cana-de-açúcar em substituição à utilização da força de trabalho manual.

A questão é paradoxal, pois, se de um lado, o trabalho nos eitos dos canaviais envolve uma série de problemas no que diz respeito ao cumprimento de direitos e garantias fundamentais, de outro, o desemprego massivo que a mecanização desencadeará traz para o Brasil inteiro a necessidade de discussões sérias a respeito de problemas sociais.

Ademais, a análise do desenvolvimento sustentável nos setores produtivos suscita debates intensos, mas no setor sucroalcooleiro o debate é mais intenso, devido às práticas antissociais e nocivas ao meio ambiente, próprias e comuns na atividade canavieira.

Dessa forma, o presente artigo pretende levantar alguns aspectos acerca da indústria canavieira e a sua polêmica introdução na agenda do desenvolvimento econômico sustentável, sob o enfoque dos direitos fundamentais do trabalhador, bem como destacar as políticas públicas e sociais propostas pelos atores envolvidos na questão.

\section{OS DIREITOS DOS TRABALHADORES NO CONSTITUCIONALISMO SOCIAL DO SÉCULO XX}

Conforme se sabe, os movimentos que suscitaram o reconhecimento da necessidade de proteção aos direitos sociais surgiram em meados do século XIX, mas a consolidação de tais direitos no constitucionalismo só ocorreu no século XX.

De fato, as demandas das massas de trabalhadores despossuídos de poder e riquezas após a Revolução Industrial romperam com a filosofia liberal e individualista, levando o Poder Público a tomar medidas interventivas diretas sobre a economia das nações industrializadas e conforme observa Dallari (1995, p. 235):

"O Estado Liberal, com um mínimo de interferência na vida social, trouxe, de início, alguns inegáveis benefícios: houve um progresso econômico acentuando, criando-se as condições para a revolução industrial: o indíviduo foi valorizado, despertando-se a consciência para a importância da liberdade humana; desenvolveram-se as técnicas de poder, surgindo e impondo-se a ideia do poder 
legal em lugar do poder pessoal. Mas, em sentido contrário, o Estado Liberal criou as condições para sua própria superação. Em primeiro lugar, a valorização do indivíduo chegou ao ultraindividualismo, que ignorou a natureza associativa do homem e deu margem a um comportamento egoísta, altamente vantajoso para os mais hábeis, mais audaciosos ou menos escrupulosos. Ao lado disso, a concepção individualista da liberdade, impedindo o Estado de proteger os menos afortunados, foi a causa de uma crescente injustiça social, pois, concedendo-se a todos o direito de ser livre, não se assegurava a ninguém o poder de ser livre. Na verdade, sob o pretexto de valorização do indivíduo e a proteção da liberdade, o que se assegurou foi uma situação de privilégio para os que eram economicamente fortes. E, como acontece sempre que os valores econômicos são colcados acima de todos os demais, homens medíocres, sem nenhuma formação humanística e apenas preocupados com o rápido aumento de suas riquezas, passaram a ter o domínimo da sociedade."

Desta forma, a concepção dos direitos sociais como fundamentais demonstram o reconhecimento de que o homem não vive isoladamente. Além disso, na condição de ser social, o homem detém o seu direito individual de liberdade, princípio basilar do liberalismo político que, no entanto, deve ser limitado.

Com efeito, só é possível se falar em Estado Democrático se for assegurada igualdade de oportunidades, a partir de condições econômicas e sociais que permitam ao indivíduo superar os seus limites individuais, pois do contrário estaremos diante de um modelo utópico de Estado.

Segundo Dallari (1995, p. 257), a ideia de Estado Democrático está relacionada aos valores fundamentais de certo povo, em determinada época em determinados lugares, assim é evidente que o Estado deve ser flexível para adaptar-se às exigências das circunstâncias em que se insere.

Lembrando que a Declaração Universal dos Direitos Humanos de 1948 marcou o início do processo de conversão universal em direitos positivos dos direitos do homem e a fundação do Estado Moderno, tal como afirmara Norberto Bobbio. Portanto, a proclamação dos direitos sociais, expressa o amadurecimento de novas exigências ou mesmo novos valores, como o bem-estar, a igualdade material e o que se chama de liberdade através ou por meio do Estado. Nas palavras de Bobbio (1992, p. 34), a Declaração Universal dos Direitos Humanos "representa a consciência histórica que a humanidade tem seus próprios valores fundamentais na segunda metade do século XX. É uma síntese do passado e uma aspiração para o futuro (...)".

Mas Bobbio (1992, p. 33-34) também destaca que os direitos sociais estão em contínuo movimento e se a proteção social advém da revolução industrial, 
é provável que o desenvolvimento tecnológico e econômico traga consigo novas demandas, incapazes de se prever por enquanto.

Conforme observam Maurício Godinho Delgado e Lorena Vasconcelos Porto (2007, p. 20) para lembrar que o advento da noção de democracia, em que a ideia e prática da liberdade material avança além das elites socioeconômicas e políticas das nações, está truncada ao advento do Estado de Bem-Estar Social, e estritamente relacionada à afirmação do trabalho e do emprego, por meio das organizações sindicais de trabalhadores e partidos de formação popular.

Mas não somente isso, além dos princípios de democracia, valorização do trabalho e emprego, justiça social e bem-estar, próprios do "Welfare State", favorecerem o indivíduo destituído de riqueza por meio da intervenção estatal nas relações sociais, o Estado de Bem-Estar Social serviu também aos interesses do próprio sistema capitalista gerando um mercado consumidor mais sólido e duradouro já que a valorização do trabalhador produz o consumidor, peça fundamentamental para a economia de mercado: "O Ebes (Estado de Bem-Estar Social) torna os respectivos países e economias melhor preparados para enfrentar o assédio das pressões internacionais e para conquistar mercados mundiais" (Delgado; Porto, 2007, p. 21-22).

Não obstante, a intervenção do Estado no campo econômico sempre fora uma constante e a ele se atribui às empreitadas do capitalismo. Mesmo no período cunhado de "liberalista" do mercado, o Estado sempre fora chamado a socorrer as imperfeições do sistema de acumulação de riquezas. Ocorre que a partir da incorporação das políticas keynesianas na economia de mercado, o Poder Público exerce esse poder por meio de motivações renovadas e mediante a dinamização de instrumentos mais efetivos. Neste sentido, Eros Grau afirma: "O Estado, no exercício de sua função de acumulação, promove a renovação do capitalismo" (Grau, 1998, p. 22). Nesse sentido, na inteligibilidade de suas afirmações, Canotilho (1998, p. 354), complementa:

"As declarações universais dos direitos tentam hoje uma coexistência integrada dos direitos liberais e dos direitos sociais, econômicos e culturais, embora o modo como os Estados, na prática, asseguram essa imbricação, seja profundamente desigual."

É desta forma que as discussões a respeito dos direitos fundamentais sociais atacam em grande parte a ausência da eficácia e aplicabilidade dos mesmos, já que é cabível ao Estado o papel de promover os direitos elencados no Título II da Constituição Federal de 1988, sobretudo no art. 6. ${ }^{\circ}$, tratador dos direitos sociais. Entretanto, tal problemática não é exatamente a abordagem do presente trabalho, o que se quer revelar no que concerne aos direitos fundamen- 
tais de cunho sociais em relação à agroindústria sucroalcooleira, diz respeito ao abandono do projeto social e as políticas neoliberais no setor, a partir da década de 90.

Ademais, o que comove os defensores de uma ordem social, ou seja, da manutenção do Estado Social de Direito é justamente a afetação das doutrinas liberais, alcunhadas de "neo", sobre direitos fundamentais sociais e não apenas a problemática da aplicabilidade dessas normas.

$\mathrm{Na}$ concepção de Ingo W. Sarlet (2001, p. 5) o Estado Social de Direito constitui aquele que realiza mediante seus procedimentos e os limites inerentes ao Estado de Direito, a Justiça Social. E tal concepção de Estado necessita que se tenha definido, o que por seu conteúdo e importância estão fora da disponibilidade dos agentes públicos, ou seja, quais são direitos não passíveis de alteração pelo próprio aparelho estatal, eis que são direitos fundamentais.

No dizer de José Afonso da Silva (2005, p. 180), os direitos fundamentais da pessoa humana são a expressão que resume os princípios sintetizadores da concepção do mundo jurídico e informa a ideologia política de cada ordenamento. O termo "direitos fundamentais" designa em nível de direito positivado as prerrogativas e instituições que a lei concretiza uma convivência digna, livre e igual a todas as pessoas, outrossim, dá forma aos direitos que devem ser reconhecidos para a sobrevivência e convivência da pessoa humana em sociedade.

Nesta via, a afirmação das doutrinas neoliberalistas e a provocação dos impactos da globalização sobre as economias nacionais tendem a produzir o enfraquecimento do poder estatal, uma desnacionalização, desestatização, desregulação e diminuição gradativa do estado sobre a economia e a sociedade, ocasionando o fortalecimento do poder econômico que retém para si o privilégio das regulações sociais.

Assim, a crise do Estado Social de Direito é a crise do Estado Nacional, ou ainda, crise da sociedade, da democracia e da cidadania, e até mesmo a crise dos direitos fundamentais e segundo Ingo W. Sarlet (2001, p. 6-7):

"Crise que - à evidência - será mais ou menos aguda, quanto maior for o impacto dos efeitos negativos da globalização econômica e da ampla afirmação do paradigma neoliberal, de modo especial nos países tidos como periféricos ou em desenvolvimento, até mesmo diante de seu grau de dependência dos países industrializados, depedência esta que tende a se tronar cada vez maior, aprofundando, por sua vez, os sintomas da crise já referida."

No mesmo diapasão, é o entendimento de André-Noël Roth (1996, p. 1516) ao sustentar que após a reconfiguração da política mundial o papel ou- 
torgado ao Estado será determinado pelo modelo de regulação social posto em prática nos países mais industrializados. Em tais países, a eficiência das regulações do Estado foram questionadas e criticadas por estudos sobre a sua ação, as políticas de desregulação se impuseram como uma resposta neoliberal à crise (crise do petróleo e consequente derrocada dos Estados de Bem-Estar Social), e não fora capaz de resolvê-la.

Desta forma, é que a distância entre a lei a realidade social, a dificuldade da aplicação de programas estatais, a interpenetração entre os domínios públicos e privados provocam reflexões e ensaios de novas práticas administrativas, levando o Estado a fazer uso de novos instrumentos de ação, por meio de uma legislação mais flexível, ou seja, leis incitativas, mesas redondas, contratos negociados, 'gentlemen agreement', leis de bases. Neste particular, André-Noël Roth explica que (1996, p. 20):

"O direito nacional adquire de maneira ampliada a forma do direito internacional. A legislação nacional perde seu caráter detalhista para limitar-se a um direito mais geral e flexível de engendrar uma particularização e uma privatização de regulação jurídica. Assistimos, de um lado, a um movimento de internacionalização do direito nacional e sua forma e, de outro lado, a um movimento de mudança, tanto no nível internacional, como também no nível infranacional e da esfera privada, da produção das normas e da legitimação."

Enfim, se os direitos fundamentais sociais são inatingíveis pelos agentes públicos, com a renovação das políticas liberalistas que pregam o alto custo dos encargos do Estado Social e os apontam como obstáculo ao progresso econômico, esses direitos passam a ser transigíveis e a proteção dos mesmos depende inexoravelmente do nível de atuação dos agentes sociais.

Sob essa perspectiva, cabe apresentar a atual conjuntura em que a agricultura canavieira se insere no novo modelo de desenvolvimento econômico, proposto pelos países industrializados em busca do ajuste às demandas do mercado consumidor atento às questões ambientais e suas consequências para os direitos fundamentais sociais.

\section{A AGRICULTURA CANAVIEIRA E AS CONTROVÉRSIAS SOBRE SUA SUSTENTABILIDADE NAS RELAÇÕES DE TRABALHO}

É de conhecimento notório que a história do Brasil está intrinsecamente relacionada à atividade canavieira. Segundo Caio Prado Jr. (2000, p. 135), a produção açucareira fora a primeira desenvolvida pelos colonizadores portugueses, suas técnicas e métodos retrógrados, como a própria queimada, copia- 
da dos indígenas, causavam diversos problemas para os agricultores da época como o esgotamento do solo e a falta de lenha, ademais, "a devastação da mata em larga escala ia semeando desertos em estéreis atrás do colonizador", a cana atingiu significativamente a fertilidade dos massapés baianos e pernambucanos no inicio da colonização.

Nesta linha de pensar, Gilberto Freyre, em Casa grande e senzala (1998, p. 25), resgata o trabalho escravo nas plantações, trato e colheita da cana, primeiro feito pelos índios, depois pelos africanos, utilizados ainda no desmatamento, abertura de caminhos e trato da terra, sempre sob o olhar dos feitores e evangelização jesuíta, que afinal permitiu a formação da sociedade patriarcal simbolizada na relação: casa grande, senzala e capela.

“(...) a monocultura latifundiária, mesmo depois de abolida a escravidão, achou jeito de subsistir em alguns pontos do país, ainda mais absorvente e esterilizante do que no antigo regime; e ainda mais feudal nos abusos, criando um proletariado de condições menos favoráveis de vida do que a massa escrava."

Por um longo período da história brasileira, que não cabe a este artigo aprofundar o setor canavieiro é marcado por suas oscilações econômicas e ajudas governamentais, no mais, tais aspectos foram levantados apenas com o intuito de demonstrar que, embora os promotores do álcool combustível venham insistindo no sucesso do setor, suas práticas estão mais parecidas com o modelo colonial do que com o modelo sustentável.

A compreensão do conceito de desenvolvimento sustentável ganha destaque após a 2. ${ }^{a}$ Guerra Mundial, em razão do surgimento da ideologia do desenvolvimento, sob o pretexto de fazer com que os países pobres adotassem um padrão de consumo semelhante ao dos praticados pelos países desenvolvidos. Esta ideia, porém, é substituída pela ideologia do neoliberalismo e a derrocada do consumismo levou o mercado "todo poderoso" a delegar a preocupação com as questões ambientais e sociais às instâncias multilaterais da Organização das Nações Unidas e do Banco Mundial (Leroy, 2008, p. 17).

De outro lado, o conceito de desenvolvimento sustentável foi construído ao longo de 15 anos, a partir de uma formulação de Maurice Strong a Ignacy Sachs. Strong, na Conferência de Estocolmo de 1972, preocupado com a dicotomia do consumo praticado pelos países do Norte e a intensa pobreza dos países entende ser necessário equalizar as diferenças para tratar da temática de desenvolvimento e meio ambiente, que não poderiam estar dissociadas. Sachs (2008, p. 10), por sua vez, cunha o termo ecodesenvolvimento como forma de se obter uma homogeneidade social para depois compreender a sustentabilida- 
de como algo capaz "de se submeter aos preceitos de prudência ecológica e de fazer um bom uso da natureza", a fim de o termo desenvolvimento sustentável se transforme em uma adjetivação "socialmente includente, ambientalmente sustentável e economicamente sustentado no tempo".

Como explica José Fernando Vidal de Souza (2011, p. 102) é a partir "da Conferência de Estocolmo em 1972 que nasceu o senso do ecodesenvolvimento, posteriormente denominado desenvolvimento sustentável, como levou o mundo a pensar a questão ecológica sob um outro prisma, através do seu lema: 'Uma Terra Só', que inclusive levou a ONU a criar o Programa das Nações Unidas para o Meio Ambiente (PNUMA)".

Assim, o termo desenvolvimento sustentável aparece em 1987 com a edição do relatório Brundtland. Este relatório publicado com o nome "Nosso futuro comum", decorre dos trabalhos realizados pela Comissão Mundial sobre o Meio Ambiente e Desenvolvimento (CMMAD), convocada pela ONU em 1982 e liderada pela primeira-ministra norueguesa Gro Harlem Brundtland, que tinha a missão de elaborar uma agenda global para mudança do comportamento ambiental.

O documento elenca uma série de princípios, direitos e responsabilidades gerais que deverão ser seguidos para a proteção ambiental e o desenvolvimento sustentável.

Em 1992, na Conferência das Nações Unidas sobre Meio Ambiente e Desenvolvimento, o termo desenvolvimento "voltou com todo seu magnetismo, alcunhado agora de sustentável".

Contudo, esse novo modelo foi entregue aos cuidados do mercado. Como afirma Jean Pierre Leroy, basta analisar o capítulo segundo do relatório da Agenda 21, resultante da Conferência intitulado de "Cooperação internacional para acelerar o desenvolvimento sustentável dos países em desenvolvimento e políticas internas correlatas", para verificar que o termo "cooperação internacional" significa, em outras palavras: mercado global, e políticas "internas correlatas" traduz-se em abertura econômica para que impulsionar os países em desenvolvimento se sustentarem. Na regra do mercado o produto visado é o lucro e este se determina pelos desejos do consumidor (LEROY, 2008, p. 17).

Nesse mesmo sentido, Lindgren Alves atribui à Conferência do Meio Ambiente e Desenvolvimento um significado para o mundo de ruptura com o ecocentrismo antimoderno e a passagem para o tecnocentrismo ecológico. A visão ecocentrista do meio ambiente é radicalmente preservacionista, separa o homem da natureza e o concebe como um inimigo e destruidor do ecossistema, enquanto na visão do tecnocentrismo ecológico, a preservação e o 
progresso ambiental está relacionado ao desenvolvimento que priorize técnicas limpas (como a substituição do petróleo para a energia solar ou eólica), ou seja, o meio ambiente está relacionado a um progresso sustentável e como enfatiza J. A. Lindgren Alves (2002, p. 34):

"A UNCED ${ }^{1}$ conseguiu, assim, consolidar o entendimento e, portanto, transmitir a mensagem de que, se, por um lado, a superpopulação é de fato voraz, a pobreza pode ser poluidora e a miséria tende a ser predatória para a natureza circundante, por outro lado, o maior responsável pela degradação ambiental planetária é o padrão insustentável de produção e consumo nas sociedades desenvolvidas - padrão que é regularmente importado pelos setores avançados dos países em desenvolvimento. Frente ao caráter compósito da degradação ambiental em escala global, uma batalha realmente eficaz para a defesa da natureza não pode ser travada pelas simples abstenções nem pela renúncia do Terceiro Mundo a ir ao encalço de suas metas de desenvolvimento. Ela deve congregar esforços gerais e cooperativos de todos os agentes, com o propósito de promover, nacional e internacionalmente, um modelo de desenvolvimento sustentável, isto é, um modelo capaz de assegurar um progresso econômico e social contínuo sem destruir as condições de vida das gerações presentes e futuras."

O desenvolvimento sustentável é o modelo em que os agentes econômicos devem se promover internacionalmente, capaz de assegurar o progresso econômico e social sem destruir as condições de vida para as gerações presentes e futuras. Conforme aduz o art. 8. ${ }^{\circ}$ da Conferência, os Estados devem reduzir e eliminar padrões insustentáveis de produção e consumo e promover políticas demográficas apropriadas. A Conferência quebrou o radicalismo ecocentrista que ainda existia na Conferência de Estocolmo de 1972 e ajudou os países desenvolvidos e em desenvolvimento a conciliar um interesse comum (Alves, J. A. L., 2002, p. 35-38).

Qual a implicância dessa ruptura? É suficiente aceitar que o modelo de desenvolvimento sustentável seja proposto pelos países industrializados e aclamados como alternativa para as questões mundiais? O Brasil vai manter-se adepto a esse modelo ou é capaz de promover a sustentabilidade de maneira democrática?

1. UNCED (United Nations Conference on Environment and Development), sigla em inglês, e CNUMAD (Conferência das Nações Unidas para o Meio Ambiente e o Desenvolvimento), sigla em português, é o nome atribuido à Conferência RIO-92 (Alves, J. A. L., 2002, p. 35-38). 
Conforme destaca José Fernando Vidal de Souza, necessário que se lance um novo olhar para a relação entre equilíbrio econômico e as preocupações sociais-ambientais, é preciso pensar nosso modelo de produção e consumo e todas as outras relações cotidianas, portanto, o "desenvolvimento sustentável pressupõe um crescimento econômico compatível com a existência dos recursos naturais, de tal forma que este seja preservado e não degradado" (2008, p. 323). Nas palavras do autor:

"Essa rede complexa enseja o surgimento de um capital mundial extremamente volátil e leva muitos dos países do Terceiro Mundo, a perder não só a parte de sua soberania, como sofrer espoliações dos seus recursos naturais e ficar mais sujeitos às instabilidades e mudanças de todo o processo produtivo, caso não ofereçam vantagens para a permanência do capital estrangeiro em seus territórios. Estas transições, aliadas aos problemas internos próprios desses países, tais como pobreza, miséria, falta de estruturas básicas de saúde, educação etc., produzem uma imensa transformação social, que conduz à perda paulatina de identidade cultural." (SouzA, 2008, p. 327)

Enfim, diante de tais colocações tem-se como coloca Sidarta Ruthes (2007, p. 34) que o desenvolvimento sustentável "deve ser promovido por meio de ações pertinentes e balanceadas, nos âmbitos econômico, ambiental e social", pois "não existe sustentabilidade sem compromisso harmônico entra essas variáveis".

Porém, as características da atividade canavieira levam a crer que o setor está interessado tão só na compreensão das demandas de mercado, eis que promove o etanol como mera alternativa para a escassez energética, enfatizando que este é produzido de maneira limpa, tal como exige a filosofia da sustentabilidade.

Esta visão, porém, não é inovadora. Vale lembrar que a crise mundial do petróleo de 1973 levou o Brasil a lançar o Programa Nacional do Álcool (Proálcool) editado em novembro de 1975 pelo Dec. 76.593, que vendia o álcool como uma saída econômica viável para a mencionada crise do petróleo, que provocou um aumento exorbitante no preço da gasolina. O mencionado projeto, porém, passou a ser uma modernização da conservadora agricultura nacional, com ajuda de incentivos governamentais diversos aos usineiros. Com isto, a utilização do etanol como combustível permitiu a continuidade da produção, eis que antes o álcool era apenas produzido como substituto da queda do mercado de açúcar (Alves, F., 1991, p. 34).

Como destacam Vianna, Wehrmann e Duarte (2007, p. 97) "apesar do sucesso comercial e técnico, esse programa não conseguiu reduzir a dependência brasileira do petróleo importado, uma vez que só pretendia a substituição da gasolina". 
Além disso, nos anos 90, a atividade canavieira passou a sofrer com a descrença do mercado consumidor no Proálcool dado o desabastecimento de etanol nas bombas de combustível, por seu turno, o Estado promovia a abertura comercial e desregulação do setor no mercado mundial.

Assim é que, em 1998, a mobilização da sociedade civil contra a queima da cana conseguiu motivar os usineiros, juntamente com o Governo do Estado de São Paulo e os representantes dos trabalhadores a celebrar o pacto chamado Acordo dos Bandeirantes fixando o ano de 2006 para o fim das queimadas (Alves, Francisco José da Costa; 2009, p. 160).

Porém, bem antes do prazo se encerrar, em 2002, a Lei estadual 11.241, de 19 de setembro, adiou o fim das queimadas para 2021 e 2031 em áreas mecanizáveis e não mecanizáveis, respectivamente (BRASIL, 2002). No entanto, em 2007, a Unica (União da Indústria do Açúcar) firmou com o goveno estadual um novo protocolo adiantando os prazos legais anteriormente estipulados para 2014 e 2017, respectivamente (BRASIL; UNICA, 2007).

Diante de tais argumentos, questiona-se se a mera eliminação das queimadas no processo de colheita será suficiente para adequar o setor à produção sustentável.

Afinal, não obstante todos os prejuízos que o fogo e a fumaça causam ao meio ambiente, à saúde da população e dos trabalhadores na época da colheita, não se pode esquecer que a cana-de-açúcar é uma planta bastante rígida, dotada de tecidos resistentes e elásticos e a sua queima, além de facilitar o corte e promover a produtividade, elimina os animais peçonhentos, evitando acidentes com os cortadores. Neste caso, de fato, apenas a máquina seria capaz de dar solução aos problemas com a saúde do trabalhador e com o meio ambiente (Ribeiro; Ficarelli, 2010, p. 50).

Com efeito, de outro lado, vale destacar que a máquina utilizada colhe entre 800 a 1.000 toneladas por dia, o que acarreta invariavelmente a substituição do trabalho de 100 homens, tendo em média que cada homem corta em média 8 e 12 toneladas diárias (RAmOs, 2007, p. 71).

Assim é que, em 2008/2009, a safra da cana colhida mecanicamente atingiu o percentual de 49,1\%; na safra 2009/2010 esse índice atingiu 55,7\% da produção. Tem-se, pois que, atualmente, mais da metade da produção sucroalcooleira é colhida por máquinas no Estado de São Paulo (BACCARIN; GabarRA; BORGES, 2010, p. 6)

Além do mais, a mecanização e a expansão da agricultura canavieira implicam em sua série de fatores que suscitam preocupações não tão somente com relação aos trabalhadores no setor, mas com problemas ligados à compactação do solo e redução de sua fertilidade, uso abusivo de agrotóxicos, concentração 
fundiária, ameaça do setor sobre a floresta amazônica, risco de aumento sobre o valor dos alimentos e ameaça à soberania alimentar. ${ }^{2}$

Vale lembrar que os diversos setores da sociedade civil estão sendo surpreendidos com maciça propaganda do agronegócio, tais como progresso, empregabilidade e responsabilidade social. De fato, os setores de comunicação transmitem constantemente essa mensagem, enquanto, na esfera política e econômica, os conglomerados agroindustriais se infiltram junto aos três Poderes Estatais, financiando campanhas políticas e decisões judiciais (CAMPOS; Campos, 2007, p. 5).

Entretanto, nas relações de trabalho da indústria canavieira, o agronegócio mantém o cenário degradante do emprego nos canaviais. Assim, sob o clima seco e quente, associado à fuligem proveniente da queimada, necessária para aumentar a produtividade e evitar picadas de animais peçonhentos, trajando um uniforme que o protege, mas aumenta a temperatura corporal, o trabalhador caminha 8.800 metros por dia, despende 366.300 golpes de podão, faz aproximadamente 36.630 flexões na perna para golpear a cana e trabalha de 8 a 12 horas por dia (Alves, F; 2006, p. 94).

Aí então os motivos que levam os cortadores de cana à morte, ao contrair doenças, a consumir drogas ${ }^{3}$ para aumentar a produtividade, tudo em prol do salário que é determinado por sua produtividade e em prejuízo de sua saúde, sua higiene e sua dignidade.

No trajeto alojamento-trabalho, são comuns os acidentes fatais no transporte dos cortadores. A alimentação é insuficiente e condições de higiene pes-

2. A recente polêmica sobre a aprovação do novo Código Ambiental demonstra as incongruências das "políticas sustentáveis" que vêm sendo adotadas na economia brasileira: as alterações propostas pelo Deputado Aldo Rebelo (PCdoB) sobre o PL 1.876, de 19 de outubro de 1999, que versa sobre mudanças no Código Florestal de 1965 fazem com que as irregularidades deixem de existir e o que era um passivo ambiental de uma propriedade rural desapareça. As modificações acerca das áreas de preservação ambiental, vegetação nativa e conceito de propriedade rural (CAPOBIANCO, 2011, p. 8-9). Vide também: Campos; Campos, 2007, em que as autoras analisam o avanço do agronegócio do país sobre a escassez de abastecimento na cesta básica de alimentos do brasileiro. Os lucros da agroindústria aumentam sua percentagem sobre o PIB (Produto Interno Bruto) do país enquanto $46,6 \%$ das famílias afirmam ter dificuldades para obter alimentos suficientes para alimentação diária (2007, p. 5).

3. Segundo o Departamento de Toxicologia da Faculdade de Medicina da Unesp de Botucatu, os cortadores de cana utilizam do crack para aumentar a produtividade, daí a expressão "estar com o diabo no corpo". Maria Aparecida Moraes Silva relembra a descrição de que o Capital ser o 'vampiro' que suga o sangue do trabalhador na fase da industrialização inglesa no século XIX (Silva, M., 2004, p. 48). 
soal quase inexistentes. Fornecimento de água é precário, mas a vigilância não fraqueja (SILVA, M., 2004, p. 53-55).

O trabalhador que não atinge a produtividade média é afastado por falta de habilidade para o trabalho. Por tal motivo, a presença de mulheres nos canaviais é mais uma exigência do sindicato do que vontade do empregador na contratação (DiEESE; MDA, 2007, p. 67). Em geral, os usineiros dão preferência aos jovens e migrantes, porque além de mais produtivos, são mais fortes, não se sindicalizam e o trabalho nos eitos se funde com a vontade de ascenção social (Novaes, 2009).

Além dos problemas diretamente associados às relações de trabalho, a grande maioria dos cortadores de cana-de-açúcar detém baixo nível de escolaridade e qualificação profissional. Ademais, o corte de cana-de-açúcar é apenas a saída que esses homens e mulheres encontram para suprir a baixa rentabilidade em seus locais de origem, já que grande parte deles retornam nos períodos da entressafra da cana.

Neste sentido, de acordo com os dados da Unica existem aproximadamente 54.000 cortadores de cana-de-açúcar migrantes temporários, número que corresponde a $40 \%$ da ocupação da mão de obra no setor.

Porém, segundo informações da Pastoral do Migrante, os cortadores de cana provenientes de outras regiões do país, principalmente da região Nordeste, representam $70 \%$ da mão de obra na indústria canavieira paulista (CARDoso, 2010, p. 17). ${ }^{4}$

Segundo a Secretaria-Geral da Presidência da República a faixa etária da maioria dos cortadores de cana está entre 30 e 39 anos e os índices se assemelham nas regiões produtoras do país. Por outro lado, quanto à escolaridade, o Nordeste apresenta os maiores índices de analfabetismo e menores índices de trabalhadores escolarizados (BRASIL, 2009, p. 11).

Tal realidade se confirma por meio dos dados do IBGE. O país ainda lida com altos índices de má qualidade da educação no campo, cuja promessa ou compromisso não bastarão. Segundo um relatório do Grupo Permanente de Trabalho de Educação do Campo do Ministério do Trabalho, com base nos dados de pesquisa realizada pelo IBGE entre o período de 1996/2002, um quinto da população encontra-se no campo, sendo que $29,8 \%$ da população adulta é analfabeta,

4. A diferença apontada pode ser explicada pelo fato da Unica considerar como migrantes apenas os trabalhadores abrigados nos alojamentos destinados para a produção da cana, enquanto a Pastoral do Migrante realiza a pesquisa nos locais de origem desses trabalhadores (CARDOSO, 2010, p. 17). 
enquanto que nos núcleos urbanos esse número chega a 10,3\%. O rendimento médio das famílias no Nordeste equivale a R \$ 186,00 enquanto no Centro-Oeste esse valor alcança um patamar de $\mathrm{R} \$ 518,00$ (BrASIL, 2009, p. 17).

Desta forma, é possível concluir que, embora o setor sucroalcooleiro desfruta de um ótimo momento e perspectiva na economia de mercado, que recentemente tenta conciliar os interesses econômicos às questões socioambientais, os trabalhadores vivem em um drama paradoxal: o trabalho precário ou o desemprego.

Nesse sentido, busca-se a partir de dados de agentes governamentais e não governamentais, bem como sindicatos e demais atores sociais envolvidos na questão, destacar as medidas que vem sendo tomadas para compensar a ameaça do desemprego aos cortadores de cana-de-açúcar, bem como nas políticas necessárias para que os direitos fundamentais desses trabalhadores sejam realmente observados.

\section{Politicas públicas para a mecanização da colheita da cana-de- AÇÚCAR}

Antes do desenvolvimento deste item, necessário se faz definir alguns aspectos próprios do mundo que cerca os cortadores de cana-de-açúcar em São Paulo para que se possa discutir as medidas políticas a serem realizadas em prol desses trabalhadores por força da iminente ameaça ao seus postos de trabalho.

A primeira questão a ser levantada já foi pontuada e diz respeito ao meio ambiente do trabalho em que vivem os cortadores de cana. O labor exaustivo, pagamento por produção, sujeição às variações climáticas, doenças respiratórias por conta das queimadas e outros problemas de saúde são pressupostos elementares para medir as consequências para o fim do corte manual da cana-de-açúcar.

O outro aspecto a ser levantado são as características desses trabalhadores. De acordo com os dados da Unica existem aproximadamente 54.000 cortadores de cana-de-açúcar migrantes temporários, valor que representa $40 \%$ da ocupação da mão-de-obra no setor. No entanto, essa informação é refutada pelos dados da Pastoral do Migrante; segundo a organização, os cortadores de cana provenientes de outras regiões do país, principalmente da região Nordeste, representam $70 \%$ da mão de obra na indústria canavieira paulista (CARDoso, 2010, p. 17). ${ }^{5}$

5. Essa diferença pode ser explicada porque a Unica considera como migrantes apenas os trabalhadores abrigados nos alojamentos destinados para a produção da cana e 
Ademais, grande parte desse contingente de trabalhadores trocou o lápis pela enxada, depois pela foice, fato que desenha um novo problema: a exigência da escolaridade e qualificação para essa categoria (RAmOs, 2007, p. 69).

A maioria dos cortadores de cana possui entre 30 e 39 anos e tais índices são semelhantes nas demais regiões produtoras do país. Por outro lado, consoante dados da Secretaria-Geral da Presidência da República (BrasIL, 2009, p. 11) a maioria dos trabalhadores empregados no corte de cana-de-açúcar no Estado de São Paulo são oriundos do Nordeste, região que apresenta os maiores índices de analfabetismo e menores índices de trabalhadores escolarizados.

Concomitantemente, no Brasil há significativa participação estrangeira na produção sucroalcooleira, além de índice altamente representativo no setor dos agronegócios, responsável pela operação da base da monocultura e insegurança alimentar dos camponeses do país.

Com efeito, segundo dados da Organização das Nações Unidas para a Agricultura e Alimentação (FAO) apresentados por Antônio Thomaz Jr., 70\% dos pobres que vivem nos campos, somente $2 \%$ têm acesso à máquinas $\mathrm{e}$ implementos, enquanto a maioria, $65 \%$, lavra a terra com suas próprias mãos. Existem aproximadamente 1 bilhão de pessoas acometidas pos desnutrição crônica sendo que 75\% vivem na zona rural (Thomaz Jr., 2007, p. 2).

Assim, existem duas alternativas para a realização de medidas políticas em prol dos cortadores de cana-de-açúcar que visem resolver os problemas apontados.

A primeira delas, aceita o projeto oficial de expansão do setor por meio do agronegócio e apresenta como solução para os trabalhadores desocupados pela mecanização a sua reintegração nos postos de trabalho ofertados em virtude da implantação de tecnologia do setor. Pode-se citar como exemplo as operações em caminhão-oficina, caminhão-comboio, caminhão-pipa, trator de esteira e veiculo de ligação campo-usina que cria cerca de 66 postos de trabalho diretos por frente de corte.

Ademais, segundo Francisco Alves, a mecanização completa irá requerer 1.194 máquinas e 78.800 novos postos de trabalho até o final do prazo estipulado pela lei para o fim das queimadas (Alves, F., 2009, p. 168).

Desta forma, o setor demandará um significativo contingente de mão de obra escolarizada e qualificada para operar no setor, habilitando os trabalha-

a Pastoral do Migrante realiza a pesquisa nos locais de origem desses trabalhadores (Cardoso, 2010, p. 17). 
dores para as atividades técnico-cognitivas. É certo que ações promotoras de cursos de qualificação já estão sendo implementados e fomentados por entes governamentais, sindicais e promotores do trabalho.

A proposta oficial, composta de 18 termos do "Compromisso Nacional para Aperfeiçoar as Condições de Trabalho no Corte de Cana", ${ }^{6}$ construidos ao longo de 17 reuniões de trabalho, demonstram que o projeto do governo para compensar os futuros desempregados pelo setor consistem em apresentar melhorias nas condições de trabalho. Entre diversas cláusulas que visam melhorar ou eliminem as práticas antissociais e trabalhistas no setor, está a qualificação e recolocação da mão de obra ${ }^{7}$ (BRASIL, 2009, p. 4).

Nesse diapasão, a Unica lançou um projeto de requalificação de cortadores de cana, denominado Projeto Renovação, patrocinado pelas empresas John Deere, Grupo Case e Syngenta, e contou com o apoio também do Banco Interamericano de Desenvolvimento (BID). O projeto visa requalificar 7.000 funcionários e ex-funcionários ligados ao corte de cana por ano, por meio de cursos profissionalizantes para atuarem ainda na indústria canavieira de motoristas canavieiros, operadores de colhedoras, eletricistas, mecânicos, soldadores, mas também em outras atividades como avicultura, jardinagem,

6. Participaram do Compromisso, a Contag, a Feraesp (Federação de Empregados Rurais Assalariados do estado de São Paulo), a Unica, o Governo Federal pela Secretaria-Geral, a Casa Civil da Presidência da República, MTE (Ministério do Trabalho e Emprego), MDA (Ministério do Desenvolvimento Agrário), MEC (Ministério da Educação e Cultura), MDS (Ministério do Desenvolvimento Social) e Mapa (Ministério da Agricultura, Pecuária e Abastecimento).

7. Acerca desse acordo, o relatório da ONG Repórter Brasil alerta: "Apesar do lançamento, em junho de 2009, do Compromisso Nacional para aperfeiçoar as condições de trabalho na cana-de-açúcar (acordo de adesão voluntária, não vinculante, assinado pelo governo e pelos setores empresarial e sindical), o país ainda carece de medidas punitivas para descumprimento da legislação trabalhista. Por exemplo, a Proposta de Emenda Constitucional (PEC) 438/2001 que prevê a expropriação das terras onde ocorreu o crime de trabalho escravo, continua paralisada no Congresso Nacional. E mesmo em usinas signatárias do Compromisso, que carece de mecanismos de monitoramento, o Ministério Público do Trabalho continua a encontrar graves irregularidades" (Centro de Monitoramento de Agrocombustíveis, 2009, p. 6). Outro relatório denuncia: em uma das maiores empresas usineiras, a Cosan que emprega mais de 40 mil pessoas em período de safra, foram encontrados quarenta e dois trabalhadores em condições precárias e semelhantes ao trabalho escravo, tendo sido aliciados por uma empresa terceirizada (Centro de Monitoramento de Agrocombustíveis, 2009, p. 13). 
construção civil, horticultura, costura, apicultura etc., conforme a demanda e oportunidade de cada região ${ }^{8}$ (UNICA, 2010).

Some-se a isso a ação do Ministério Público do Trabalho que tem sido imprescindível na garantia de direitos fundamentais da pessoa do trabalhador na agricultura canavieira, por meio das ações civis públicas, obrigando as usinas a cumprirem uma série de exigências efetivas para a concretização de direitos laborais. ${ }^{9}$

Um exemplo de ação mais abrangente, voltada para a melhoria da qualidade de vida dos cortadores de cana-de-açúcar, é a iniciativa do Ministério Público do Trabalho na criação do Programa Nacional de promoção do Trabalho Decente no Setor Sucroalcooleiro, para impedir que a expansão da produção canavieira ocorra em desacordo com os valores sociais do trabalho (MinistéRIO Público do Trabalho, 2011).

A promoção de cursos de qualificação, todavia, é ineficiência para garantia de emprego desses cortadores; é preciso, ainda, que as entidades sindicais e órgãos públicos se mobilizem para incentivar a estabilidade das relações de trabalho na agroindústria com uma política de emprego séria e efetiva, que promova os direitos na direção contrária às teorias da flexibilização com o fim do salário por produção, fim da intermediação da mão de obra e fim do emprego temporário.

8. Segundo informações disponíveis no site da Unica, cerca de 2.000 trabalhadores rurais que atuam hoje na colheita manual da cana-de-açúcar já foram treinados pelo Projeto RenovAção para funções de operador de colhedora, motorista canavieiro, soldador, eletricista e mecânico nas seis regiões do Estado de São Paulo em que o Projeto está presente: Ribeirão Preto, São José do Rio Preto, Araçatuba, Presidente Prudente, Piracicaba e Bauru (Unica, 2010).

9. Merece relevo a decisão proferida em ação civil pública, processo 0086862.2006.5.15.0039, ajuizada pelo Ministério Público do Trabalho da 15. ${ }^{a}$ Região em face da Usina São José, perante a Vara do Trabalho de Capivari, prolatada em 30.04.2007. O Juiz Marcos Menezes Barberino Mendes decidiu em sede de tutela antecipada pôr fim às terceirizações da empresa a partir da safra de 2007, o que representou um marco na atuação judiciária trabalhista, não somente porque coibiu a empresa a terceirizar qualquer dos seus serviços, aplicando os efeitos da decisão a todo grupo econômico em nível nacional, como também ofereceu como alternativa à sentença a promoção de cursos de alfabetização dos cortadores de cana. A sentença confirmou o que foi decidido na tutela antecipatória e a Usina recorreu, conquanto, em termos de execução provisória, as audiências demonstram fatores como desinteresse do trabalhador por encontrar-se cansado ao fim do dia, dificuldades com deslocamento de alunos e professores, reivindicação de instalação de salas de aulas nos alojamentos e realização de audiências públicas para debater o assunto. 
A inexistência de políticas trabalhistas torna os projetos de capacitação provisórios e ineficazes que tendem a reproduzir o doloroso processo de reestruturação produtiva vista no setor nos anos $90 .^{10}$

No entanto, há uma outra possibilidade para promover a cidadania e a efetivação dos direitos fundamentais dos trabalhadores na agricultura canavieira, mas tal caminho envolve uma série de medidas complexas que necessitam de força política e mobilização social, pois se relacionam com as diversas instâncias de poderes do país exigem reformas de base historicamente sonegadas na sociedade brasileira.

A reforma agrária e as políticas intervencionistas ocorridas em países como Austrália e Cuba, são exemplos de medidas que viabilizaram a mecanização completa da agricultura canavieira com a promoção da agricultura familiar, qualificação e formação profissional dos trabalhadores garantindo a ocorrência de progresso técnico e a participação dos trabalhadores (GuTELman, 1975, p. 81; Guedes, 2000, p. 68).

Desta maneira, é necessário ter em conta o que afirma José Eli da Veiga ao que diz respeito da temática ora examinada sob a luz do conceito atual de desenvolvimento sustentável (2008, p. 208):

"Em meio a tantas linhas especulativas, o que parece se destacar é uma forte visão convergente de que as sociedades industriais estão entrando em uma nova fase de sua evolução. E que essa transição será tão significativa quanto aquela que tirou as sociedades europeias da ordem social agrária e levou-as às ordem social industrial. Ao mesmo tempo, as diversas versões sobre o 'desenvolvimento sustentável' parecem estar muito longe de delinear, de fato, o surgimento dessa nova utopia de entrada no terceiro milênio."

Assim, o fomento de políticas públicas para a agricultura familiar pode ser concretizado por meio da ocupação das áreas não mecanizaveis, cujo segundo dados do Ipea, representam $20 \%$ de toda as áreas ocupadas pela cana no país. Com isso, 1 milhão de hectares podem ser liberados para a agricultura familiar que, por sua vez, necessitará da instituição de políticas de financiamento e

10. Há de se destacar o PL 234/2007, do Deputado Federal João Dado que acrescenta o art. 13-A na Lei 5.889/1973, para dispor sobre a atividade dos trabalhadores no corte de cana. Entre as disposições consta a previsão do adicional de insalubridade em grau máximo, adicional de penosidade e regime especial de jornada, reduzindo o período de 8 horas diárias para 6, somando-se 36 horas semanais, conquanto o projeto encontra-se engavetado na Comissão de Agricultura, Pecuária, Abastecimento e Desenvolvimento Rural (CAPADR), da Câmara de Deputados, desde 15.07.2009 (BRASIL, 2007). 
créditos. O sucesso desta empreitada, porém, depende da seriedade e afinco das pessoas envolvidas, que podem efetivamente resolver o problema do desemprego e a redução do risco que a expansão a agricultura canavieira representa para a segurança alimentar. ${ }^{11}$

Portanto, a questão posta pressupõe o enfrentamento do modelo ditado pelo agronegócio e aceito, passivamente, na esfera pública, que assegura o domínio da sociedade pelo capital, estruturado sob uma base ideológica defensora do desenvolvimento e da sustentabilidade. Este modelo deixa de promover mudanças profundas na realidade da economia de mercado ora dominante, tal como se constata no projeto do etanol, uma repaginação do Proálcool, agora erigido como biocombustível, que só tem promovido o enriquecimento das grandes corporações.

Além disso, existem outras propostas que visam o fomento de políticas para a agricultura familiar e camponesa na cadeia de produção e comercialização dos agrocombustíveis como estimular o associativismo, cooperativismo e a economia solidária, qualificação e assistência técnica, extensão ao crédito rural, seguro e garantia de preços mínimos, bem como construção de miniusinas ${ }^{12}$ e infraestrutura local e acesso aos equipamentos, promover autonomia dos agricultores etc. (REDRIP; FASE, 2008, p. 136).

Assim, as entidades sociais, sindicais, organizações não governamentais, entes públicos e a iniciativa privada têm um papel fundamental a ser desempenhado

11. Vale trazer, segundo a Declaração Final do Fórum Mundial de Soberania Alimentar, assinado pela Via Campesina, realizado em Havana/Cuba, em 2001, soberania alimentar significa: "O direito dos povos de definir e usar suas próprias políticas e estratégias sustentáveis de produção, distribuição e consumo de alimentos que garantam o direito de alimentação para toda a população com base na pequena e média produção, respeitando suas próprias culturas e diversidade de modos camponeses, pesqueiros e indígenas de produção agropecuária, de comercialização e de gestão dos espaços rurais, nos quais a mulher desempenha um papel fundamental. A soberania alimentar favorece a soberania econômica, política e cultural dos povos. Defender a soberania alimentar é reconhecer uma agricultura com camponeses, indígenas e comunidades pesqueiras, vinculadas ao território, propriamente orientada à satisfação das necessidades dos mercados locais e nacionais (CAMPos; Campos, 2007, p. 8).

12. Vale destacar que algumas pesquisas já tem se voltado para a produção de álcool em escalas menores, havendo instalação e operação de pequenas destilarias autônomas em diversos lugares do país, como exemplo a de Jundiaí e São Carlos, nesses casos a produção não é a única atividade, ela está articulada à produção de forragens para gado bovino, biogás, biofertilizante, aproveitamento do vinhoto, uso do bagaço excedente como combustível e outras atividades que poderiam aumentar a lucratividade do empreendimento, tendo sido designado esse modelo como "Sistema Integrado de Produção de Alimentos e Energia” - Sipea (Ortega; Watanabe; Cavalett, 2008, p. 2). 
no "desenvolvimento sustentável", com promoção de políticas que fortaleçam a igualdade construindo assim um verdadeiro Estado Democrático de Direito.

\section{CONSIDERAÇÕES FINAIS}

A sustentabilidade ora aclamada pela sociedade civil e os entes públicos apresenta pontos controvertidos. Se de um lado as preocupações ambientais tomam conta da agenda política de desenvolvimento dos países de terceiro mundo e aparentam medidas positivas em prol de um projeto social, como ocorre no caso do setor sucroalcooleiro brasileiro em busca da promoção do etanol combustível no mercado de produção energia limpa e renovável, de outro, podem representar apenas o novo discurso liberal mascarado de sustentável, em prol da mantença do padrão de consumo dos países industrializados, em detrimento do desenvolvimento econômico e social dos países do terceiro mundo.

A vasta bibliografia existente sobre as medidas de mecanização da colheita, a importância e emergencialidade da discussão sobre a temática podem contribuir para a melhoria do meio ambiente e da vida dos trabalhadores envolvidos no corte da cana-de-açúcar. Porém, constata-se que, na atualidade, o avanço da tecnologia do setor ainda não produziu os efeitos sociais e econômicos para a sociedade civil e aos trabalhadores.

Embora exista uma tradição nas mobilizações sociais em relação a questão ora tratada, percebe-se que aproximação do prazo para o fim da utilização da queimada como método da colheita, acelera as preocupações com os trabalhadores da cana-de-açúcar que ocupam esse cruel posto de trabalho.

As poucas políticas públicas realizadas estão a indicar que o governo e a iniciativa privada optaram por promover cursos de qualificação para a recolocação dos cortadores de cana-de-açúcar após a mecanização.

Entretanto, a singela realização de cursos de qualificação suscita mais dúvidas do que efetivas soluções para o setor. De fato, neste setor, a grande maioria dos trabalhadores é submetida às condições precárias de trabalho, baixos salários, além de detentores de baixos níveis de escolaridade. Estes fatores demonstram que tais trabalhadores praticamente não terão condições concretas de preencherem os novos cargos que irão surgir com o avanço da tecnologia na agricultura canavieira.

Além disso, as propostas dos demais entes sociais que visam a garantia da cidadania e a concretização dos direitos fundamentais desses trabalhadores, como o incentivo a agricultura familiar, uma política de reforma agrária séria e prioritária, escolarização no campo etc., também parecem não alcançar os projetos oficiais. 
Entretanto, as políticas públicas são necessárias para a promoção da igualdade social, mas não podem se limitar a um exercício retórico, ideológico e utópico. Assim, devem ser convertidas em ações concretas que viabilizem um novo modelo de desenvolvimento que não se confunde com singelo crescimento econômico e permita um projeto social não excludente e assegure a todos os trabalhadores uma qualidade de vida.

\section{REFERÊNCIAS}

Alves, Francisco José da Costa. Mecanização do corte de cana crua e políticas públicas compensatórias: indo direto ao ponto. Revista Ruris. vol. 3. n. 1. p. 153-178. Campinas: Ceres-IFCH/Unicamp/Nead, jan.-mar. 2009.

. Por que morrem os coradores de cana? Revista Saúde e Sociedade. vol. 15. n. 3. p. 90-99. São Paulo, set.-dez. 2006.

Modernização da agricultura e sindicalismo: lutas dos trabalhadores assalariados rurais da região canavieira de Ribeirão Preto. Tese de doutorado, Campinas, Universidade Estadual de Campinas, 1991.

Alves, J. A. Lindgren. As conferências sociais da ONU e a irracionalidade contemrpoânea. In: ___ Teubner, Gunther; Alvim, Joaquim Leonel de Rezende; RüDIGER, Dorothee Susanne. Direito e cidadania na pós-modernidade. Piracicaba: Unimep, 2002. p. 19-90.

Baccarin; José Giacomo; Gabarra, José Jorge; Borges, Júlio Cesar. Avanço da mecanização canavieira e alterações na composição, na ocupação, na sazonalidade e na produtividade do trabalho em empresas sucroalcooleiras. Informações Econômicas. vol. 40. n. 9. São Paulo, set. 2010.

Boвbio, Norberto. A era dos direitos. Trad. Carlos Nelson Coutinho. Rio de Janeiro: Campus, 1992.

Brasil. Projeto de Lei 234/2007. Acrescenta art. 13-A na Lei 5.889, de 8 de junho de 1973, para dispor sobre a atividade dos trabalhadores no corte de cana. Disponível em: [www.camara.gov.br/sileg/Prop_Detalhe.asp?id=342571]. Acesso em: 13.01.2011.

São Paulo. Lei 11.241, de 19 de setembro de 2002. Dispõe sobre a eliminação gradativa da queima da palha da cana-de-açúcar. Disponível em: [www.al.sp.gov.br/repositorio/legislacao/lei/2002/lei\%20n.11.241,\%20 de\%2019.09.2002.htm]. Acesso em: 19.08.2010.

Secretaria-Geral da Presidência da República. Termo de Compromisso Nacional para aperfeiçoar as condições de trabalho na cana-de-açúcar. Brasília, 2009. Disponível em: [www.secretariageral.gov.br/noticias/Publi/compromisso_nacional/view]. Acesso em: 22.11.2010.

; Unica - União da Indústria do Açúcar. Protocolo Agroambiental. São Paulo, 04.06.2007. Disponível em: [www.unica.com.br/content/show. asp $?$ cntCode $=\{$ BEE106FF-D0D5-4264-B1B3 7E0C7D4031D6 $\}]$. Acesso em: 12.02.2011. 
Campos, Christiane Senhorinha Soares; Campos, Rosana Soares. Soberania alimentar como alternativa ao agronegócio no Brasil. Revista Scripta Nova: Revista Electrónica de Geografía y Ciencias Sociales. vol. 11. n. 245 (68). p. 1-14. Barcelona: Universidad de Barcelona, ago. 2007.

Canotilho, José Joaquim Gomes. Direito constitucional e teoria da Constituição. Coimbra: Almedina, 1998.

Capobianco, João Paulo R. O código do atraso. Le Monde Diplomatique Brasil. ano 4. n. 46. p. 7-8. São Paulo: Le Monde Diplomatique Brasil, maio 2011.

Cardoso, Terezinha de Fátima. Cenários tecnológicos e demanda da capacitação da mão-de-obra do setor agrícola sucroalcooleiro paulista. Dissertação de mestrado, Campinas, Universidade Estadual de Campinas, 2010.

; Oliveira, Julieta T. A.; Braunbeck, Oscar A. Capacitação da mão-de-obra no setor sucroalcooleiro paulista: necessidades e motivações. Informações Econômicas. vol. 40. n. 10. p. 24-32. São Paulo: Instituto de Economia Agrícola, out. 2010.

Centro de Monitoramento dos Agrocombustiveis. ONG Réporter Brasil. O Brasil dos agrocombustíveis, cana 2009: impactos das lavouras da cana sobre a terra, o meio e a sociedade. São Paulo. out. 2009. Disponível em: [www. reporterbrasil.org.br/documentos/zoneamento_cana_reporterbrasil_out09. pdf]. Acesso em: 20.11.2010.

Dallari, Dalmo de Abreu. Elementos de teoria geral do Estado. São Paulo: Saraiva, 1995.

Delgado, Maurício Godinho; Porto, Lorena Vasconcelos. O estado de bem-estar social no capitalismo contemporâneo. In: (orgs.). O Estado de Bem-Estar Social no século XXI. São Paulo: Ed. LTr, 2007.

DiEesE - Departamento Intersindical de Estudos Sócio-Econômicos; MDA Ministério do Desenvolvimento Agrário. Estudos sobre as convenções coletivas da categoria canavieira. São Paulo, Pernambuco e Góias, 1989-2005. São Paulo/Brasília: Dieese/MDA/Nead Estudos, 2007.

Fausto, Boris. História concisa do Brasil. São Paulo: USP, 2008.

FreYre, Gilberto. Casa grande e senzala. Rio de Janeiro: Record, 1998.

Grau, Eros Roberto. A ordem econômica na Constituição de 1988. 5. ed. São Paulo: Malheiros, 1998.

GuEdEs, Sebastião Neto Ribeiro. Verticalização da agroindústria canavieira e a regulação fundiária no Brasil: uma comparação internacional e um estudo de caso. Tese de doutorado, Campinas, Universidade Estadual de Campinas, 2000.

Gutelman, Michel. A agricultura socializada em Cuba. 2. ed. Lisboa: Prelo, 1975.

Leroy, Jean Pierre. Contextualização e problematização dos agrocombustíveis no Brasil. In: Rede Brasileira pela Integração dos Povos. Agrocombustíveis e agricultura familiar e camponesa: subsídios ao debate. Rio de Janeiro: Redrip/ Fase, 2008. 
; Wilkinson, John; Herrera, Selena; Bermann, Célio; Moreno, Luis Macedo; Domingues, Mariana Soares; Rosenberg, Renato. Sistematização das apresentações e dos debates ocorridos no seminário. In: REDE BRASILEIRA PELA InTEGRAÇ̃̃o dos Povos. Agrocombustíveis e a agricultura familiar e camponesa: subsídios ao debate. Rio de Janeiro: Rebrip/Fase, 2008. Disponível em: [www.boelllatinoamerica.org/download_pt/Biocombustiveis2008_ Agrocombustiveis_e_a_agricultura_familiar.pdf]. Acesso em: 01.02.2011.

MPT - Ministério Público do Trabalho. Programa Nacional de Promoção do Trabalho Decente no Setor Sucroalcooleiro. Disponível em: [http://portal. mpt.gov.br/wps/wcm/connect/983fe500467907acb8bbff757a687f67/sucro. pdf?MOD=AJPERES\&CACHEID=983fe500467907acb8bbff757a687f67] . Acesso em: 18.05.2011.

Novaes, José Roberto. Trabalho nos canaviais: jovens entre a enxada e o facão. Revista Ruris. vol. 3. n. 1. p. 103-127. Campinas: Ceres-IFCH/Unicamp/ Nead, jan-mar. 2009.

Ortega, Enrique; Watanabe, Marcos; Cavalett, Otávio. A produção de etanol em micro e mini-destilarias. Agência de Informação da Embrapa. São Paulo, ago. 2008. Disponível em: [www.agencia.cnptia.embrapa.br/Repositorio/ mini-usina-Ortega_000fxf2i83n02wyiv80soht9hu9eu0yp.pdf]. Acesso em: 18.05.2011.

Prado JR., Caio. Formação do Brasil contemporâneo. São Paulo: Publifolha/ Brasiliense, 2000.

Procuradoria Regional do Trabalho da 15. a Região. Acordo com Nova América garante direitos inéditos aos cortadores de cana. Notícias. Campinas, 01.10.2010. Disponível em: [www.prt15.mpt.gov.br/site/noticias.php?mat_ $\mathrm{id}=10654$ ]. Acesso em: 14.11.2010.

RAmos, Pedro. O futuro da ocupação na agroindústria canavieira do Brasil: uma discussão dos trabalhos disponíveis e um exercício de estimação. Informações Econômicas. vol. 37. n. 11. São Paulo, nov. 2007.

Ribeiro, Helena; FICARELl, Thomaz Ribeiro. Queimadas nos canaviais e perspectivas dos cortadores de cana-de-açúcar em Macatuba. Revista Saúde e Sociedade. vol. 19. n. 1. p. 48-63. São Paulo, 2010.

Roth, André-Noël. O Direito em crise: fim do Estado Moderno? In: Faria, José Eduardo (org.). Direito e globalização econômica: implicações e perspectivas. São Paulo: Malheiros, 1996.

Ruthes, Sidarta. Inteligência competitiva para o desenvolvimento sustentável. São Paulo: Peirópolis, 2007.

SAchs, Ignacy. Prefácio. In: VeIgA, José Eli da. Desenvolvimento sustentável - Desafio do século XXI. 3. ed. Rio de Janeiro: Garamond, 2008.

SARLET, Ingo Wolfgang. Os direitos fundamentais sociais na Constituição de 1988. Revista Diálogo Jurídico. ano I. vol. I. n. I. p. 1-46. Salvador: VLex Brasil, abr. 2001. 
Silva, José Afonso da. Curso de direito constitucional positivo. 25. ed. São Paulo: Malheiros, 2005.

Silva, Maria Aparecida de Moraes. Se eu pudesse eu quebraria todas as máquinas. In: ; Antunes, Ricardo. O avesso do trabalho. São Paulo: Expressão Popular, 2004.

Souza, José Fernando Vidal de. Os direitos difusos e coletivos: o meio ambiente. In: Lemos Filho, Arnaldo; Barsalini, Glauco; Vedovato, Luís Renato; Mellim FILho, Oscar. Sociologia do direito. 3. ed. Campinas: Alínea, 2008.

Água: fator de desenvolvimento e limitador de empreendimento. São Paulo: Modelo, 2011.

Thomaz Jr., Antônio. Trabalho, reforma agrária e soberania alimentar: elementos para recolocar o debate da luta de classes no Brasil. Revista Scripta Nova: Revista Electrónica de Geografía y Ciencias Sociales. vol. 11. n. 245 (46). p. 1-16. Barcelona: Universidad de Barcelona, 2007.

UnicA. Projeto RenovAção: 4 em cada 10 alunos requalificados já estão trabalhando. Notícia. São Paulo, 17.12.2010. Disponível em: [www.unica. com.br/noticias/show.asp? nwsCode $=\{$ AE33C9D1-BBBF-48FD-92FA-01146D88808A\}]. Acesso em: 31.01.2011.

VeIgA, José Eli da. Desenvolvimento sustentável - Desafio do século XXI. 3. ed. Rio de Janeiro: Garamond, 2008.

Vianna, João Nildo de S.; Wehrmann, Magda Eva S. de F; Duarte, Laura M. G. Os desafios para o desenvolvimento sustentável no Brasil. In: ; NAScimento, Elimar Pinheiro do (orgs.). Dilemas e desafios do desenvolvimento sustentável no Brasil. Rio de Janeiro: Garamond, 2007.

\section{Pesouisas do Editorial}

\section{Veja também Doutrina}

- Ação civil pública - Queimada de cana-de-açúcar - Degradação do meio ambiente Competência, de Álvaro Luiz Valery Mirra - RDA 1/238; e

- Ação civil pública - Utilização de fogo para a colheita da cana-de-açúcar - Obrigação de não fazer reconhecida, de Álvaro Luiz Valery Mirra - RDA 8/186.

\section{Veja também Jurisprudência}

- Ação civil pública - Queima de palha de cana-de-açúcar sem autorização da autoridade competente: RDA 64/402. 